\title{
Lack of Support in Medical Device Regulation within Academia
}

\author{
Rita Hendricusdottir, Azad Hussain, William Milnthorpe and Jeroen HM Bergmann *(D) \\ Natural Interaction Lab, Department of Engineering Science, Institute of Biomedical Engineering, \\ University of Oxford, Oxford OX1 3PJ, UK; rita.hendricusdottir@eng.ox.ac.uk (R.H.); \\ azad.hussain@eng.ox.ac.uk (A.H.); william.milnthorpe@eng.ox.ac.uk (W.M.) \\ * Correspondence: jeroen.bergmann@eng.ox.ac.uk
}

Citation: Hendricusdottir, R.;

Hussain, A.; Milnthorpe, W.;

Bergmann, J.H. Lack of Support in Medical Device Regulation within Academia. Prosthesis 2021, 3, 1-8. https://doi.org/10.3390/prosthesis 3010001

Received: 26 September 2020

Accepted: 4 January 2021

Published: 6 January 2021

Publisher's Note: MDPI stays neutral with regard to jurisdictional clai$\mathrm{ms}$ in published maps and institutional affiliations.

Copyright: $\odot 2021$ by the authors. Licensee MDPI, Basel, Switzerland. This article is an open access article distributed under the terms and conditions of the Creative Commons Attribution (CC BY) license (https:// creativecommons.org/licenses/by/ $4.0 /)$.

\begin{abstract}
New medical technologies can transform healthcare, and automation of processes is becoming increasingly ubiquitous within the patient care sector. Many innovative ideas arise from academia, but regulations need to be taken into account if they want to reach the market and create a real impact. This is particularly relevant for applied fields, such as prosthetics, which continuously generates cutting-edge solutions. However, it remains unclear how well the regulatory pathway is supported within universities. This study applied a data-driven assessment of available online information regarding support of medical device regulations within universities. A total of 109,200 URLs were screened for regulatory information associated with universities in the UK and the USA. The results show that based on available online data, 55\% of the selected universities in the UK and $35 \%$ in the USA did not provide any support for medical device regulations. There is a big discrepancy between universities in terms of the available support, as well as the kind of information that is made accessible by the academic institutes. It is suggested that increasing support for regulatory strategies during the early phases of research and development will likely yield a better translation of technologies into clinical care. Universities can play a more active role in this.
\end{abstract}

Keywords: clinical technology; medical devices; FDA; translation research; regulatory science; research support; innovation; medical device regulation (MDR)

\section{Introduction}

New innovative technologies can help to solve unmet clinical needs or provide benefits beyond existing healthcare solutions. The process of innovation is dynamic and multifaceted even at the early stages of problem exploration [1]. Innovation itself lies at the heart of research, and universities often aim to commercialize the scientific or technological knowledge that has been generated. It has already been shown that universities play a key role in generating innovative activities in public organizations [2] and that technology transfer from universities contributes in an important way to economic growth by making companies more innovative [3]. Moreover, companies are increasingly relying on discoveries made in academia [4] to progress their commercial endeavors. Collaborations between the healthcare industry (e.g., pharmaceutical companies) and academic institutions have now started to become standard practice [5].

However, the true impact of healthcare technology can only occur if the patient is positively affected beyond research, which requires technology to be compliant with all the relevant regulations. Nevertheless, healthcare innovation is already very resourceintensive, with relatively high upfront costs for research and development [6,7], and regulations further add to the required cost and time of successful innovation.

In order to bring a medical technology to the market, innovators need to follow regulations, ensuring safety and performance requirements are met. However, the regulatory process can be very onerous and time-consuming and requires innovators to understand the language of the legislation. The development of novel concepts for medical devices, 
such as prosthetics, often starts in the academic environment. Early engagement with regulations would further streamline the translation of research.

Prosthetic research is a highly innovative field that ranges from fundamental research on potential assistive technologies, such as magnetic- or electrorheological fluid-based gripping methods [8,9], to applied studies on, e.g., neural-connected sensory prosthesis or new tactile feedback approaches $[10,11]$. It is very important to be aware of the regulations whenever these technologies are developed for clinical use. Prosthetic development pathways can be optimized for translation from academia to industry if appropriate support is given. Emerging prosthetic technologies have the potential to reach large populations of patients and add to their quality of life. During the development of these technologies, innovators/academics should be taking regulation into consideration to ensure that these prosthetic technologies are safe and perform well, which in turn will maximize patient impact. Nonetheless, proficiency of the regulations has been identified as a key knowledge deficit for academics entering the medical device industry [12,13].

It remains unclear to what extent universities are providing appropriate support in terms of regulations. This paper is a first assessment of the level of support available based on data that are accessible in the public domain. A systematic search strategy was applied to provide a comprehensive overview of the current state of play. The main aim was to determine how many universities have a web presence related to medical device regulation and what kind of support is offered. It was found that there is a large discrepancy between universities regarding the support that was offered, which potentially impacts the ability of academics to translate their prosthetic technologies into real clinical change.

\section{Results}

To determine how many universities have a web presence related to medical device regulations, a total of 109,200 uniform resource locators (URLs) were assessed across 330 universities in both United Kingdom (UK) and United States of America (USA). The results showed that 53 out of 119 (45\%) universities in the UK had a web presence for medical device regulation. However, in the USA, 103 out of $159(65 \%)$ universities had an online presence on regulations (Figure 1A).
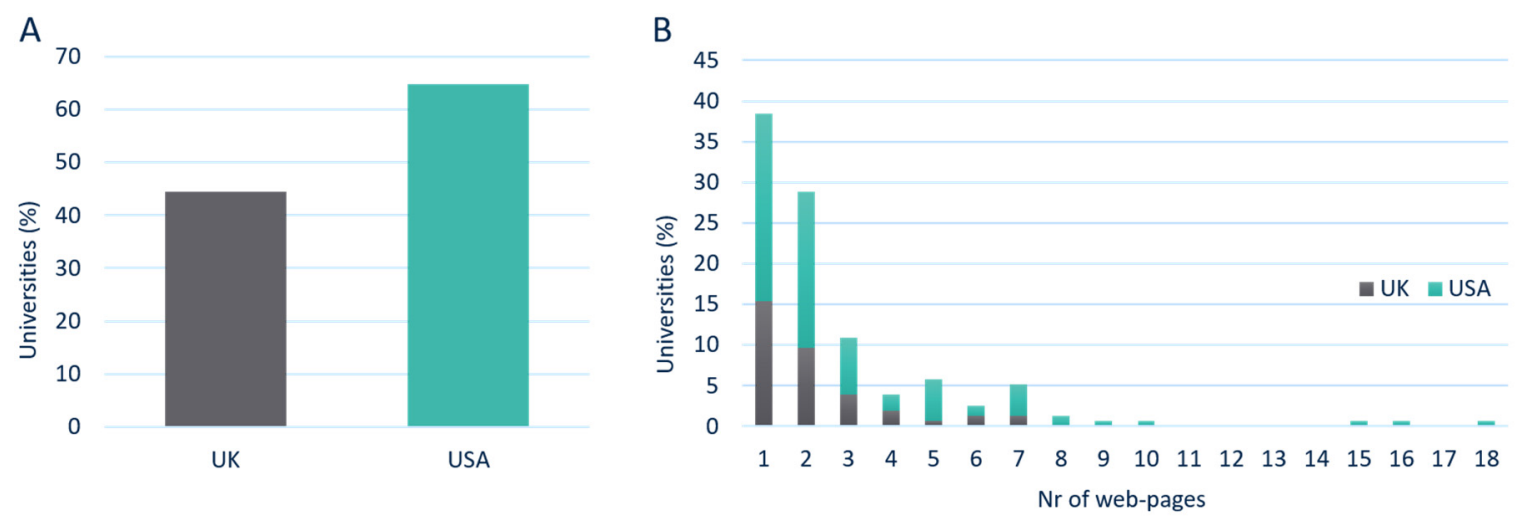

Figure 1. Results showing how many universities have regulatory web presence; (A) percentage of universities per country that mentioned regulation; (B) number of URLs mentioning regulation across all universities that had some kind of web presence on this topic.

From the 156 universities with a regulatory web presence, a total of $38 \%$ only had a single URL, $29 \%$ had two URLs, and the remaining $33 \%$ had 3 or more pages available. The maximum number of URLs found across all UK universities was 7, while this was 18 for the USA (Figure 1B).

The data showed that $34 \%$ of all pages could be classified as primary resources, followed by $27 \%$ that mentioned a degree course. In $16 \%$ of the URLs, professional development was mentioned, and $22 \%$ of the webpages was focused on secondary resources 
(Figure 2A). Of all URLs found, the frequency of regulatory support provided within UK universities was relatively comparable between secondary resources (8\%), degree courses $(9 \%)$, and primary resources $(7 \%)$. The least mentioned topic in the UK was related to professional development (3\%). On the other hand, USA universities mainly mentioned regulation as a primary resource ( $27 \%$ of the total number of webpages found). This was higher than other resources, such as degree courses (19\%), professional development $(13 \%)$, and secondary resources $(14 \%)$. Not every university was found to provide regulatory support across all four types of content descriptors (primary resources, degree courses, professional development, or secondary resources).

A

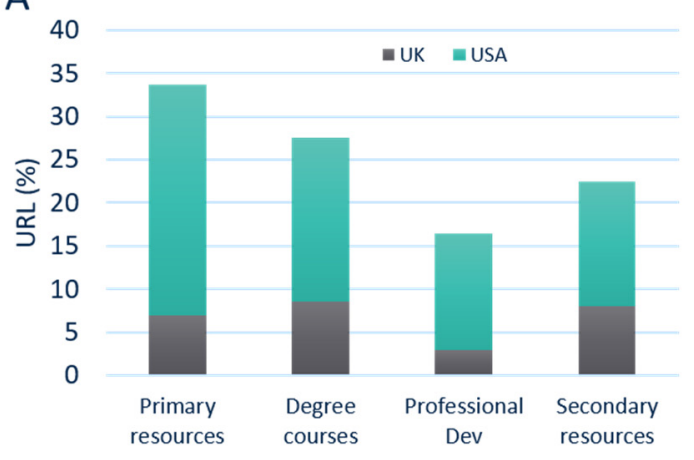

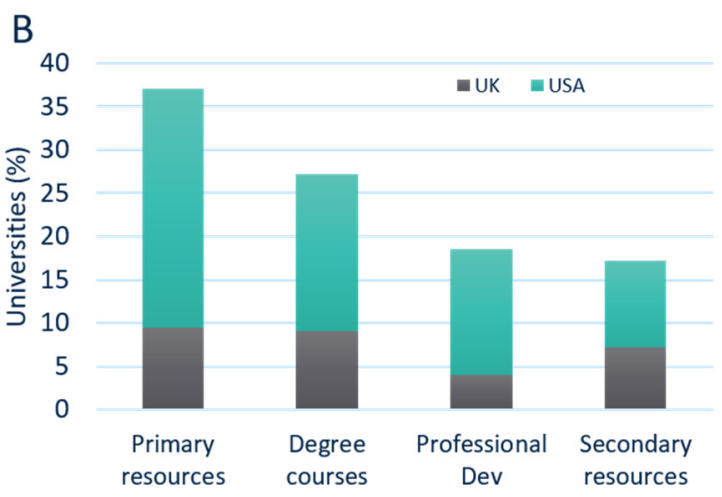

Figure 2. Results showing what kind of regulatory support is provided by academia. (A) This graph shows the percentage of URL's that link to one of the four content categories: primary resources, degree courses, professional development and secondary resources; (B) This graph shows the percentage of Universities that provide a link to one of the aforementioned four regulatory content categories.

Next, the type of regulatory support universities reference on their websites was explored. The data revealed that, of all the universities that had regulatory web presence (156 universities), 37\% mentioned regulation as a primary resource (this $\mathrm{w} \backslash \mathrm{s} 28 \%$ in the USA and $9 \%$ in the UK). This was higher than the number of universities that mentioned regulation in the description of their degree courses (27\% in total, $18 \%$ in the USA, and $9 \%$ in the UK), professional development (19\% in total, $14 \%$ in the USA, and $4 \%$ in the UK), and as a secondary resource (17\% in total, $10 \%$ in the USA, and $7 \%$ in the UK), as shown in Figure 2B.

In the UK, regulation was part of the title in 10 courses and 4 modules, indicating that regulation was a fundamental part of the course. In 14 degree courses, regulation was only covered as a subsection of a module. The USA offered 67 degree courses, of which 22 were undergraduate courses and 45 were postgraduate courses. In 30 of those courses, regulation was mentioned in the title of the course or course module, with 33 courses only mentioning regulation as part of the course module (Table 1).

Table 1. Level of regulatory presence within a degree course.

\begin{tabular}{llll}
\hline \multicolumn{1}{c}{ Level } & UK & & USA \\
\hline Within a title of a course & 4 & & 11 \\
Within a title of a course module & 10 & & 19 \\
Within a subsection of a course module & 14 & 33 \\
Referenced without a clear link to the course work & 4 & 4 \\
Total & 32 & 67 \\
\hline
\end{tabular}

A further differentiation can be made at the departmental level (Figure 3). This study found that over half (52\%) of all the degree and professional development courses were provided by engineering departments, with 14\% located in the UK and $38 \%$ in the USA. Just under a quarter $(24 \%)$ of these were provided by medicine departments $(6 \%$ in the 
UK and $18 \%$ in the USA), followed by pharmacology and biological sciences departments ( $7 \%$ in the UK and $11 \%$ in the USA). In the USA, the following departments also provided regulatory courses: Law $(4 \%)$, Business $(2 \%)$, and others $(2 \%)$.

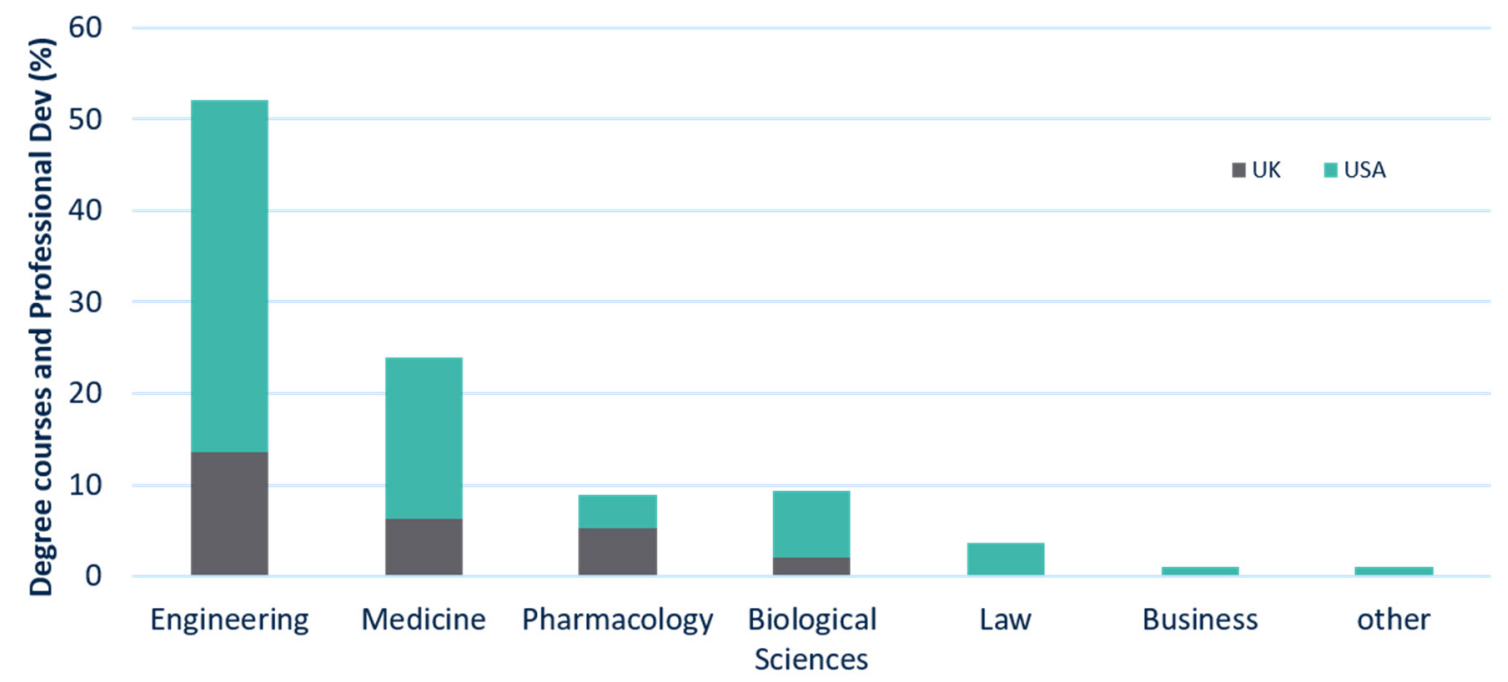

Figure 3. Percentage of degree and professional development courses for specific departments within universities.

Overall, the results show that $45 \%$ of the UK's universities have a regulatory web presence, whereas this is $65 \%$ of the universities in the USA. The main support universities provide is on primary resources, which represents established resources such as links to guidelines, standards, books, etc. In addition, the USA offer more than double the number of degree courses (67) compared to the UK (32) on this topic, while most of the taught courses, workshops and seminars are provided by engineering departments.

\section{Discussion}

Regulation of medical devices is recognized as an important subject within the scientific community, as it ensures the development of effective, safe, and beneficial devices for the end user [13]. Established companies in the MedTech sector have a lot of experience in the field of regulations, as it directly influences their operations. They have resources dedicated to regulations, both to inform and guide R\&D, manufacturing, and marketing. However, for academics or their spinouts, these kinds of resources are not as accessible, with widely varying levels of support available at different institutes. Therefore, the main aim of this study was to objectively determine how many universities provide support around medical device regulations, verifiable by their online presence on this topic. The study showed that $45 \%$ of the UK's universities have a regulatory web presence, whereas many more universities in the USA cover this topic $(65 \%)$. This study has also provided an insight into the kind of support that is available in academia. It showed that overall, the main support universities provide is on primary resources. This potentially makes sense as it provides access to information from well-established sources often generated outside of the university and thus provides a low-cost solution regarding information exchange. However, there is a difference between the USA and the UK in terms of what kind of resources are available for regulatory support. In general, the USA seem to focus more on primary resources and degree courses when compared to the UK. The inclusion of this topic within degree courses, in particular, provides a suitable manner to build capacity. Improving the knowledge and skills of people is important in the process of developing, strengthening, and maintaining public safety [14].

It should be noted that the total number of selected universities within the UK and the USA is different. In the UK, there are 171 recognized universities in total, but only universities (119) that submitted a Research Excellence Framework (REF) in one or more categories relevant to medical device regulation were included in this study. In the USA, 
there are more than 4000 degree-granting post-secondary institutions, but of these, there are only 261 research universities [15]. The included institutes consisted of 159 universities which were identified based on recognized associations [16,17]. Within the data, there could be a bias toward more research-oriented universities. The universities selected for both the UK and USA were obtained from well-defined resources. However, it should be noted that caution should be exercised when making any direct comparison between the UK and USA data. The universities entered in this study have not been weighted for the quality or quantity of their academic work which focuses on medical devices. However, it can be argued that all universities that directly (or indirectly) work within the field of medical products should be thinking about regulations. Nonetheless, the availability of (financial) resources within a university is still likely to be an important factor in terms of what kind of support can be offered. It should also be noted that the data represent a relevant but small portion of all international universities.

It is interesting to see that the integration of regulatory education within courses mainly happens at the level of modules. This provides a "regulatory viewpoint" of a certain degree topic but is unlikely to create an in-depth understanding of the regulations. Most regulatory experts gain education (and experience) outside of academic institutions. This approach can create barriers in terms of social mobility and capacity building within this field.

The observation that engineering departments are at the forefront of offering courses might not be very surprising when we consider the fact that engineers play a key role in the development of medical devices. Even so, these technologies are often brought to market by multidisciplinary teams. The regulatory journey connects to so many disciplines that other departments might also want to consider introducing more of their students to regulations. Regulations are ideally placed to be taught across departments in a multidisciplinary manner, and more universities might want to consider this approach.

Future studies could start to focus on how representative these findings are globally. This will help with determining how big the differences are with other regions and quantifying gaps between low-, middle-, and high-resource countries. Recently, it has also been highlighted that low-and middle-income countries (LMICs) are struggling with developing an appropriate healthcare technology regulatory policy that fits the local societal context and needs [18]. Allowing for more (online) resources to be available to the community will also strengthen the understanding of this topic more globally.

In addition, the data presented in this study can be further verified by directly asking universities about their regulatory content. However, it should be noted that many academics do not necessarily know exactly what kind of support is provided across the whole organization. This is due to the fact that support originates from a range of different groups within a university, including research services, research labs, tech transfer offices, and knowledge exchange initiatives. Therefore, our study provides a robust preliminary assessment of the current state of play in the UK and the USA.

There is a strong need to provide suitable prosthetic solutions in LMICs, and the application of additive manufacturing has been widely reported within this field. Nevertheless, many of these devices do not meet the end users' needs and lack clear data with regard to their performance $[19,20]$. There is often a lack of understanding of the pathway that would lead to CE marking or FDA approval for these new technologies [20]. The CE Mark (an abbreviation of "Conformit Europene") indicates that a (medical) device can be sold into the European Economic Area having been assessed to meet relevant safety, health and environmental protection requirements. The Food and Drug Administration (FDA) oversees the approval of medical devices in the USA. This lack of pathway understanding reiterates the importance of integrating regulatory support throughout the prosthetic research and development process, which should include developments that take place at universities.

Regulatory science itself is evolving as well, and new tools are being created to help innovators to navigate the regulators [21]. These developments will assist with the creation 
of a more inclusive support structure for all universities, as these tools can be easily made accessible online to a wider community. The data have clearly shown that there is indeed an interest in academia to provide this kind of support, and it is likely that this will be a growing field in the future. Adopting a proactive regulatory strategy for the prosthetic technologies that researchers and innovators would like to develop will generate more appropriate and robust solutions.

\section{Materials and Methods}

A systematic search was applied using Google Search (GS), which has been noted as an important resource for grey literature, such as institutional and governmental information [22]. GS was used as this is currently the most widely used search engine in the world, having had, as of March 2020, a 92\% market share. The following settings were used: private results set to "do not use private results", safe search filters off, results per page set at a 100 links per search page view, region settings on current region (UK), and language set as English. In order to quantify what type of regulatory support academia provides, the inclusion criteria were used as shown in Table 2.

Table 2. Description of content classification mentioning medical device regulation.

\begin{tabular}{ll}
\hline Primary Resources & $\begin{array}{l}\text { All resources that directly provide information on regulations } \\
\text { such as links to experts, guidelines, standards, books, blogs, } \\
\text { etc. }\end{array}$ \\
\hline \multirow{2}{*}{ Degree Courses } & $\begin{array}{l}\text { Undergraduate and postgraduate courses that mention } \\
\text { regulations. Postgraduate courses consist of pre-master, } \\
\text { master courses, and integrated master programs. }\end{array}$ \\
\hline Professional Development & $\begin{array}{l}\text { Consisting of non-degree courses, workshops, seminars, } \\
\text { webinars, and/or conferences. }\end{array}$ \\
\hline Secondary Resources & $\begin{array}{l}\text { Resources that mention regulations without the intent of } \\
\text { providing regulatory information or contain indirect } \\
\text { information such as job advertisements, public relation } \\
\text { articles, research group descriptions, and descriptions of } \\
\text { facilities or research. }\end{array}$ \\
\hline
\end{tabular}

The search terms comprised the official university name and the term "medical device regulations". This term was chosen as this study wanted to explore medical device regulation specifically, as opposed to medicine regulation or other regulations that universities might mention. The only exclusion criterion was journal articles, as this paper focused on the (practical) support offered. However, research groups were included to capture the general interest in regulations within a university.

The higher education institutes included in this study were universities from the United Kingdom (UK) and United States of America (USA). The list of universities for the UK was obtained from REF2014 [23,24], which consists of a published report that contains the quality assessment of research in UK higher education institutions. The inclusion criterion was universities that submitted a Research Excellence Framework (REF) in one or more of the following categories: Clinical Medicine; Public Health, Health Services, and Primary Care; Allied Health Professions, Dentistry, Nursing and Pharmacy; Psychology, Psychiatry, and Neuroscience; Biological Sciences; Chemistry; Physics; Computer Science and Informatics; Aeronautical, Mechanical, Chemical, and Manufacturing Engineering; Electrical and Electronic Engineering, Metallurgy, and Materials; or General Engineering. In total, 119 UK universities were included. The list of included USA universities was based on the American Association of Universities (AAU) [17] and Oak Ridge Associated Universities [16], which meant that 159 USA universities were entered in this study.

Once the search term was entered, the first four hundred links were assessed in order to identify URLs associated directly with the university, e.g., based on the web domain address. For the UK, this would be in the form of "university web name.ac.uk", and for 
the USA, it was "university web name.edu". Universities websites that contained the aforementioned search terms were opened and reviewed. Only webpages that mentioned regulations in the context of medical device regulations were taken into account. These webpages are referred to as URLs that have an online presence on regulations.

With regard to the publication date of information that is presented on the websites examined, no time limit was placed on this criterion. Consequently, archived information, when visible to the public, was also included. All the searches were undertaken in the time period of 12 February 2020 to 28 April 2020, and data were recorded and analyzed in Microsoft Excel (v2016, Microsoft, Redmond, WA, USA) and MATLAB (MATLAB R2020a, Mathworks, Natick, MA, USA). Corrections were made for any duplicate information (for example, two links pointing to the same webpage).

Author Contributions: Conceptualization, J.H.M.B.; methodology, R.H., A.H., and J.H.M.B.; data collection, R.H., A.H., and W.M.; formal analysis, R.H., A.H., and W.M.; data curation, R.H., J.H.M.B, A.H., and W.M.; writing-original draft preparation, R.H., A.H., and J.H.M.B.; writing-review and editing, R.H., J.H.M.B, A.H., and W.M.; visualization, R.H. and W.M.; supervision, J.H.M.B.; project administration, R.H. and J.H.M.B.; funding acquisition, J.H.M.B. and R.H. All authors have read and agreed to the published version of the manuscript.

Funding: This research was funded by the European Institute of Innovation \& Technology (EIT) Health and supported by the National Institute for Health Research (NIHR) Oxford Biomedical Research Centre (BRC).

Institutional Review Board Statement: Not applicable.

Informed Consent Statement: Not applicable.

Data Availability Statement: Publicly available datasets were analyzed in this study. This data can be found using the aforementioned search strategies.

Conflicts of Interest: The authors declare no conflict of interest.

\section{References}

1. Soliman, E.; Mogefors, D.; Bergmann, J.H.M. Problem-driven innovation models for emerging technologies. Health Technol. 2020. [CrossRef]

2. Demircioglu, M.A.; Audretsch, D.B. Public sector innovation: The effect of universities. J. Technol. Transf. 2019. [CrossRef]

3. García-Vega, M.; Vicente-Chirivella, Ó. Do university technology transfers increase firms' innovation? Eur. Econ. Rev. 2020. [CrossRef]

4. Arora, A.; Belenzon, S.; Patacconi, A. The decline of science in corporate R\&D. Strateg. Manag. J. 2018. [CrossRef]

5. Schuhmacher, A.; Gassmann, O.; Hinder, M. Changing R\&D models in research-based pharmaceutical companies. J. Transl. Med. 2016. [CrossRef]

6. Rettig, R.A. Medical innovation duels cost containment. Health Aff. 1994. [CrossRef] [PubMed]

7. Kleinke, J.D.; McGee, N. Breaking the bank: Three financing models for addressing the drug innovation cost crisis. Am. Health Drug Benefits 2015, 8, 118.

8. Hartzell, C.M.; Choi, Y.T.; Wereley, N.M.; Leps, T.J.G. Performance of a magnetorheological fluid-based robotic end effector. Smart Mater. Struct. 2019. [CrossRef]

9. Radice, I.; Bergmann, J.H.M. Conceptual exploration of a gravity-assisted electrorheological fluid-based gripping methodology for assistive technology. Bio Des. Manuf. 2019. [CrossRef]

10. Graczyk, E.L.; Resnik, L.; Schiefer, M.A.; Schmitt, M.S.; Tyler, D.J. Home use of a neural-connected sensory prosthesis provides the functional and psychosocial experience of having a hand again. Sci. Rep. 2018. [CrossRef] [PubMed]

11. Alshaibani, F.; Thompson, M.S.; Bergmann, J.H. Experimental Analysis of a Novel, Magnetic-Driven Tactile Feedback Device. Prosthesis 2020, 2, 25-38. [CrossRef]

12. Curran, D.; van Egeraat, C.; O'Gorman, C. Inherited competence and spin-off performance. Eur. Plan. Stud. 2016, 24, 443-462. [CrossRef]

13. Scannell, P.; Cormican, K. Spinning out of control? How academic spinoff formation overlooks medical device regulations. J. Technol. Manag. Innov. 2019, 14, 82-92. [CrossRef]

14. Liu, B.; Sun, Y.; Dong, Q.; Zhang, Z.; Zhang, L. Strengthening core public health capacity based on the implementation of the international health regulations (IHR) (2005): Chinese lessons. Int. J. Heal. Policy Manag. 2015. [CrossRef] [PubMed]

15. USA Research Universities. Available online: https://education.stateuniversity.com/pages/2366/Research-Universities.html (accessed on 4 June 2020). 
16. Oak Ridge Associated Universities. Available online: https://www.orau.org/university-partnerships/consortium-members.html (accessed on 4 June 2020).

17. American Association of Universities. Available online: https://www.aau.edu/who-we-are/our-members (accessed on 4 June 2020).

18. Kale, D. Mind the gap: Investigating the role of collective action in the evolution of Indian medical device regulation. Technol. Soc. 2019. [CrossRef]

19. Diment, L.E.; Thompson, M.S.; Bergmann, J.H.M. Three-dimensional printed upper-limb prostheses lack randomised controlled trials: A systematic review. Prosthet. Orthot. Int. 2018, 42. [CrossRef] [PubMed]

20. Vujaklija, I.; Farina, D. 3D printed upper limb prosthetics. Expert Rev. Med. Devices. 2018. [CrossRef] [PubMed]

21. Bergmann, J.; Hendricusdottir, R.; Lee, R. Regulatory navigation: A digital tool to understand medical device classification pathways. Compr. Biotechnol. 2019, 5, 167-172. [CrossRef]

22. Hagstrom, C.; Kendall, S.; Cunningham, H. Googling for grey: Using Google and Duckduckgo to find grey literature. In Proceedings of the Abstracts of the 23rd Cochrane Colloquium, Vienna, Austria, 3-7 October 2015.

23. REF2014. Available online: https://www.ref.ac.uk/2014/ (accessed on 10 December 2020).

24. United Kingdom Recognized Bodies. Available online: https://www.gov.uk/check-a-university-is-officially-recognised/ recognised-bodies (accessed on 4 June 2020). 